\title{
Optimization of turning parameters of Aluminum 6351 T6 using Taguchi decision making tech- nique
}

\author{
Shofique Ahmed $^{\mathrm{a}^{*}}$ and Rajesh Arora ${ }^{\mathrm{a}}$
}

\begin{tabular}{l}
${ }^{a}$ Department of Mechanical Enginee \\
\hline C H R O N I C L E \\
\hline Article history: \\
Received: October 1, 2017 \\
Received in revised format: No- \\
vember 16, 2017 \\
Accepted: June 4, 2018 \\
Available online: \\
June 4, 2018 \\
\hline Keywords: \\
Turning process \\
Surface Roughness \\
Material Removal Rate \\
Taguchi's Method \\
Signal to Noise ratio \\
ANOVA
\end{tabular}

\section{Introduction}

Turning process is a machining practice where the cutting tool is a tool bit which does not rotate and illustrates path of the tool which is helical by displacing linearly and the work piece spins. The tool moves literally in a straight path, sometimes along different curves and angles, but in most cases they travel in linear path. Turning can be external as well as internal. Internal turning process is also called as boring operation, where the tool moves internally at the workpiece (generation of holes, internal threads etc.). In the same way when the turning tool cuts the face of a workpiece where the tool is kept in a perpendicular position with the workpiece it is termed as facing operation. In a traditional lathe machine turning is

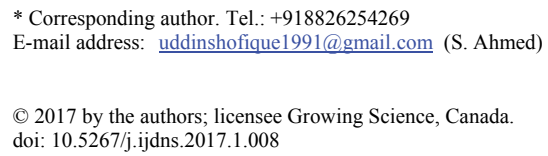


carried out manually, and frequently demands steady surveillance of operator, or using CNC lathe machine which, in which the process is automated. CNC is an automation known as computer numerical control (besides turning, CNC can be used for wide range of other form of machining operations).

In turning process, the workpiece which is a rigid material spins and cutting tool travels across all three axes of motion and produces defined depths and diameters. For lathes of earlier times it was quite difficult to produce complex shapes and structures; although since the introduction of CNC it has become easier to produce different complex geometries since $\mathrm{CNC}$ uses computerized tool-path.

Taguchi's method is an efficient statistical design tool to design the experiments with minimal variance. It is dependent on the orthogonal array (OA) of number of experiments which allows organizing the control parameters optimally. OA yields a number of unbiased experimental setting (i.e. number of experiments are less). In Taguchi's approach some logarithmic function of the required output is used termed as Signal to Noise Ratio (S/N ratio) which performs as an intent function in the process of optimization. Taguchi's method aids in the determination of optimum results and data analysis. To estimate process parameters optimally, Taguchi's method adopts $\mathrm{S} / \mathrm{N}$ ratio which is a ratio of mean aka signal to the standard deviation aka noise. This $\mathrm{S} / \mathrm{N}$ ratio is controlled by the process quality description or the products which have to be improved. Generally, the following standard S/N ratios are used: Higher-the-Better (HB), Nominal-is-Best (NB) and Lower-the-Better (LB). S/N ratio considers the mean as well as the variability. Taguchi's robust design approach has been adopted by many US and UK based companies over the years because of the fact that it is an effort for improving design robustness and product quality. Taguchi's robust design approach allows an improvement of quality of products by decreasing the influence of deviation without discarding the causes. Taguchi's method uses orthogonal array to design the experiments. There are several commonly used orthogonal array tabulated as below.

Table 1

$\mathrm{L}_{4}$ Orthogonal array

\begin{tabular}{|c|c|c|c|}
\hline \multirow[b]{2}{*}{ Run } & \multicolumn{3}{|c|}{ Factors } \\
\hline & $\mathrm{A}$ & B & $\mathrm{C}$ \\
\hline 1 & 1 & 1 & 1 \\
\hline 2 & 1 & 2 & 2 \\
\hline 3 & 2 & 1 & 2 \\
\hline 4 & 2 & 2 & 1 \\
\hline
\end{tabular}

Table 2

L ${ }_{9}$ Orthogonal array

\begin{tabular}{|c|c|c|c|c|}
\hline \multirow[b]{2}{*}{ Run } & \multicolumn{4}{|c|}{ Factors } \\
\hline & A & B & $\mathrm{C}$ & D \\
\hline 1 & 1 & 1 & 1 & 1 \\
\hline 2 & 1 & 2 & 2 & 2 \\
\hline 3 & 1 & 3 & 3 & 3 \\
\hline 4 & 2 & 1 & 2 & 3 \\
\hline 5 & 2 & 2 & 3 & 1 \\
\hline 6 & 2 & 3 & 1 & 2 \\
\hline 7 & 3 & 1 & 3 & 2 \\
\hline 8 & 3 & 2 & 1 & 3 \\
\hline 9 & 3 & 3 & 2 & 1 \\
\hline
\end{tabular}

The column of OA represents the factor and its corresponding levels and each row of OA represents the experimental run which is conducted at a given setting of the factors. The independency of selecting levels of each factor is totally up to the experimenters however most frequently two or three levels of the factors are selected.

Analysis of Variance (ANOVA) is a statistical approach for developing impetus comparisons between two or more means; the yield results using this method can be tested to predict whenever powerful symbolic correlation exists between the variables. ANOVA is an assemblage of statistical models and their combined 
measure where the inspected variance of a special variable is divided into components imputable to various provenances of variation. ANOVA is efficacious in confrontation of two, three or more means.

\section{Review of literature}

The controllable process parameters that influence a turning operation considered in this current work are NR, DOC, FR and CS. Their influences on the two responses viz. removal rate of material and roughness of the surface have been studied. MRR and $\mathrm{R}_{\mathrm{a}}$ in turning are affected by various factors. Some of these factors are use of cutting fluids, chatter, work piece setup, stability of machine tool, cutting edge angles of the tool, NR, cutting time, DOC, CS, unstable built-up edge, material hardness, material characteristics, feed rate, etc. Roy et al. (2017) selected Taguchi's L27 approach for three turning variables viz. CS, FR and DOC and optimized the parameters for MRR and $\mathrm{R}_{\mathrm{a}}$ on a CNC lathe machine. In this work they used SAE 1024 material and a carbide cutting tool. They observed the MRR and $\mathrm{R}_{\mathrm{a}}$ and developed the succession of optimum cutting parameters. Kuramand Ozcelik (2015) used Taguchi's experimental design approach to find the effects of $\mathrm{CS}, \mathrm{FR}$ and DOC on machining output namely cutting forces (CF), $\mathrm{R}_{\mathrm{a}}$ and wear of the tool in micro-milling of Ti6Al4V an aerospace material (titanium and nickel based super-alloy). Investigation of micro milling output parameters were accomplished by using ANOVA method. They proposed a regression approach that identifies the relation connecting input parameters and output responses where experimental data were fed into the model for the prediction of output responses which eliminates the requirement of experimental setup. And at last they determined the efficiency of regression model using correlation coefficient; predicted and experimental data was compared.

Zerti et al. (2017) performed an experimental optimization study of CNC dry turning of AISI D3 steel selecting Taguchi's method. DOC, FR, CS, NR and major cutting edge angle were selected as input parameters. They used a Taguchi's approach to intend the optimization investigations. They used ANOVA to obtain the foremost influence on output parameters viz. Cutting power and $R_{a}$. Sahoo et al. (2017) selected response surface methodology (RSM) to design an experiment of DOC, FR and CS on aluminum alloy 63400 for optimizing variation of tool and $\mathrm{R}_{\mathrm{a}}$. Workpieces were machined by using carbide tool in dry environment. Analysis was executed by using ANOVA method and process parameters were optimized by WPCA method. Said et al. (2016) predicted the optimal machining parameters viz. FR, DOC and CS adopting Taguchi's method on aluminum silicon alloy AlSi. They imposed ANOVA to find out the characteristic performance of the process parameters in measuring the tool life during milling operations. They concluded by developing an arrangement of optimum CS, FR and DOC for longer life of the tool. Mia and Dhar (2016) studied the impacts of high temperature coolant jet and material hardness on wear of the tool, cutting temperature and $\mathrm{R}_{\mathrm{a}}$ by adopting Taguchi's method over a dry turning of three types of hardness steel viz. 56 HRC, $48 \mathrm{HRC}$ and 40 HRC. Taguchi's optimization 'smaller the better' was applied as optimization principle and they applied ANOVA to find out the impacts of factors controlling the process. Their study showed that high- pressure coolant jet is flourishing in tumbling wear of the tool, $\mathrm{R}_{\mathrm{a}}$ and cutting temperature.

Cicek et al. (2015) investigated the parameters of drilling on surface and hole and cryogenic treatments in dry drilling of AISI 304 stainless steel. They determined the control parameters viz. speed of the spindle and feed rate to provide better smoothness of the surface and roundness error by using Taguchi's method. Then RSM was applied to find the optimum roundness error and surface roughness as a function of heat treatments and parameters of drilling implemented to the drilling experiments. Gupta and Kumar (2015) investigated a turning process of unidirectional glass fibre reinforced plastic (UD-GFRP) composite. The machinability of the turning process was analyzed, where they used Taguchi's approach for designing the experiments. They selected various variables like DOC, cutting environment (cooled, wet and dry), CS, NR, tool cutting edge angles, FR and tool rake angle to analyze their influence on output responses. They modelled the two response variables i.e. removal rate of materials and roughness of the surface by selecting principal component analysis (PCA). Lin et al. (2015) optimized multiple quality characteristics viz material removal rate, overcut and electrode depletion for achieving an improved surface roughness excellence of a Ti-6Al-4V alloy using micro electrical discharge machining. Selvaraj el al. (2014) performed an investigation on dry turning of two diverse orders of duplex stainless steel having nitrogen alloys in it by selecting Taguchi's method to improve the 
turning variables with the application of ANOVA and signal to noise ratio. They concluded cutting speed as the most influencing parameters in response to tool wear.

Chandramouli et al. (2014) examined the influence of most favourable process parameters (current, pulse off time and pulse on time) of Electric Discharge Machining on RENE80 nickel super alloy material on roughness of the surface, wear of the tool and removal rate of the material. Taguchi's technique was adopted to propose the experimentations and ANOVA was applied for the analysis of input process variables and to obtain the most influencing parameters. Jayaraman (2014) optimized turning parameters on AA6063 T6 aluminum alloy with multiple responses viz. surface roughness, material roundness; based on Taguchi's technique and Gray rational analysis. Lodhi and Agarwal (2014) optimized the machining condition for surface roughness on WEDM (wire electric discharge machining) of AISI D3 steel adopting Taguchi's approach. ANOVA was implemented to predict the significant influences of machining variables on $\mathrm{R}_{\mathrm{a}}$. Asiltürk and Neşeli (2012) performed a turning operation of AISI 304 stainless steel with CNC machine to determine the improved conditions for cutting and roughness of the surface as well as proposing a mathematical correlation with the usage of response surface methodology (RSM). The capability of that correlation was confirmed by performing ANOVA approach. Krishnakant et al. (2012) optimized the MRR on a CNC turning of EN24 steel taking into account of the turning variables like FR, DOC and CS. The experiment was intended adopting Taguchi's method; $\mathrm{S} / \mathrm{N}$ ratio- larger the better was adopted for the analyze purpose; $\mathrm{S} / \mathrm{N}$ ratio was calculated using Minitab software.

Alihan et al. (2010) conducted a multi-response improvement for turning variables viz. consumption of power, $\mathrm{R}_{\mathrm{a}}, \mathrm{NR}, \mathrm{FR}, \mathrm{DOC}$ and CS adopting Taguchi's technique. Gray relation grade was obtained from $\mathrm{S} / \mathrm{N}$ ratio. Based on those values ANOVA was implemented to predict the most significant variables for $\mathrm{R}_{\mathrm{a}}$ as well as power consumption on a CNC turning operation. Günay and Yücel (2013) tried to concentrate on the cutting condition of the alloy named as white cast iron which was obtained at 62HRC and 50HRC hardness level for improving the average surface roughness by adopting Taguchi's approach for experimentation. CNC lathe used for machining, using cubic boron nitride and ceramic as a cutting tool. $\mathrm{S} / \mathrm{N}$ ratio was used for best possible cutting state. Asilturk et al. (2012) conducted a statistical approach of Taguchi's technique to optimize roughness on a CNC turning. Surface roughness was examined using RSM (response surface methodology) for various cutting variables such as CS, FR and DOC. Suitability of proposed mathematical correlation was confirmed by analysis of variance method. Kivak et al. (2014) performed an evaluation of Hadfield steel using $\mathrm{L}_{18}$ Taguchi method and regression analysis while the impact of machining variables on the $\mathrm{R}_{\mathrm{a}}$ as well as flank wear were disclosed by ANOVA. Linear and quadratic regression analysis has been used which shows the predicted value and measured value were almost close to each other. The study of Verma et al. (2012) show that maximizing the production and quality of the machined parts had a greater impact on metal based industry where cutting speed plays a significant role in producing lower surface finish. Afflicted with lowest surface roughness and for picking up the optimum cutting condition he has used the Taguchi method with conducting 9 experiments.

The analysis of Sarikaya et al. (2014) show as the evaluation of surface roughness is very strenuous so various amalgamation of cutting condition are developed to estimate the turning parameters. Cooling condition which is a distinctive parameter has chosen alongside of CS, DOC and FR for evaluation of mean maximum height $(\mathrm{Rz})$ and mean roughness (Ra) while machining AISI 1050 steel. Mathematical model has developed under Taguchi's approach for formulating input machining variables using ANOVA which gives importance of Ra and Rz through response surface methodology. Camposeco-Negrete et al. (2013) came out with realistic approach i.e. machine tools has a greater impact on environment in terms of energy consumption which has to be optimized. A distinctive approach has made for selecting the response variable over the cutting parameters e.g. CS, FR and DOC for optimization of consumption of energy. A technique employed for minimizing the consumption of energy in contrast with FR which results higher the FR, lower the consumption of energy but accelerates to higher roughness of the material surface.

Hamdan et al. (2012) performed an experimental investigation on CNC turning of stainless steel. From their study they concluded that based on the cutting tool material the surface roughness fluctuates. A coated carbide tool used for the machining of stainless steel which will provide a lower surface roughness and the cutting 
performance will enhance. A mathematical model of Taguchi $\mathrm{L}_{9}$ has adopted for optimization compiled with $\mathrm{S} / \mathrm{N}$ ratio response and analysis of variance which will figure out the impedance coming on the way for optimization according to cutting force and surface roughness. Kant and Sangwan (2014) used statistical approach on sustainability over environment is a major issue for all the industries. However for fulfilling the customer demand the surface finish to be enhancing which implies a greater consumption of energy. A statistical approach made to diminish the roughness of the surface and consumption of power i.e. individual part manufacturing which uses GRA (grey relational analysis) compiled with response surface methodology (RSM) and principal component analysis and for analysis ANOVA has been proposed. A new analysis coming into picture that considering the idle cutting time the power consumption will minimize up to some extend which states the reduction of peak load will decreases the power consumption. Rao et al. (2013) reported that how the cutting variables like DOC, FR and CS had relevance over $\mathrm{R}_{\mathrm{a}}$ and $\mathrm{CF}$ while machining a work piece material of AISI 1050 steel with a ceramic tool named $\mathrm{Al}_{2} \mathrm{O}_{3}+\mathrm{TiC}$ matrix. A systematic approach of Taguchi $\left(\mathrm{L}_{27}\right)$ was used to perform the experiment on a $\mathrm{CNC}$ lathe which shows a greater impact of feed rate over the surface roughness.

Elbah et al. (2013) checked the surface roughness using two different methods i.e. by taking unconventional method of inserting wiper with conventional inserts. However it implies a great result of surface quality over the conventional ceramic insert using a Taguchi $\left(\mathrm{L}_{27}\right)$ orthogonal array for experimentation. Sreenivasulu et al. (2013) focused on end milling of a material named glass fibre reinforced polymeric composite to see the effect cutting variables like CS, FR and DOC over quality check of the surface and delaminating damage. They concluded with an experimental approach that CS and DOC gives a marginal difference over surface quality by a Taguchi design. Selvaraj et al. (2010) stated from the past few decades the industries are showing enormous interest towards the stainless steel as it has an excellent corrosion resistance. AISI 304 Austenitic steel has chosen for the dry turning to see the consequences on the cutting variables such as CS, FR and DOC over the quality of surface. Taguchi technique has been employed for experimentation along with the S/N ratio and ANOVA for analyzing the effectiveness however the machine tool of tungsten carbide used where a coating of $\mathrm{TiC}$ and $\mathrm{TiCN}$ applied.

These studies make obvious that Taguchi's approach provide an excellent choice for identifying the optimal roughness of surface at a specific arrangement of cutting variables in a $\mathrm{CNC}$ turning operation.

\section{Problem Description}

This current study represents the experimental study of optimization of various CNC turning parameters and their effects on MRR and surface roughness. Experiments are designed using Taguchi's L 9 orthogonal array and statistical analysis is performed using analysis of variance approach.

\subsection{Objectives and Methodology}

1. Predicting the various influence of various $\mathrm{CNC}$ turning parameters on roughness of the surface and removal rate of material.

2. Performing Taguchi's method and ANOVA on multiple responses to determine the optimum parameters and most influencing parameters.

The methodology adopted for the proposed work is as follows

1. Initial study to determine various controllable and uncontrollable parameters,

2. Selection of work material based on literature,

3. Selection of parameters, responses and their levels,

4. Selection of experimental layout using Taguchi' method,

5. Conduction of experiment,

6. Measurements of responses using standard equipment,

7. Analysis of data using statistical tool. 


\subsection{Assortment of turning parameters and their levels}

From the literature survey various parameters which influence on surface quality and production rate are determined, those parameters are controllable and uncontrollable parameters, from which more influencing parameters are selected.

1. Cutting speed or speed of the spindle (CS) in rpm,

2. Feed rate (FR) in $\mathrm{mm} / \mathrm{min}$,

3. Depth of cut (DOC) in $\mathrm{mm}$,

4. Nose radius (NR) in $\mathrm{mm}$.

Table 3

Selected values of four factors with three levels for experiment

\begin{tabular}{cccc}
\hline Parameters/factors & \multicolumn{3}{c}{ Levels } \\
\cline { 2 - 4 } & 1 & 2 & 3 \\
\hline CS & 450 & 600 & 750 \\
FR & 0.15 & 0.2 & 0.25 \\
DOC & 0.2 & 0.4 & 0.6 \\
NR & 0.4 & 0.8 & 1.2 \\
\hline
\end{tabular}

Machinery and Accessories under consideration are as

1. In this study, a Carbide cutting tool having four flutes is selected for turning.

2. Aluminum 6351-T6 is the working material, it is precipitation hardening aluminum alloy, with silicon, magnesium, manganese and zinc as its foremost elements.

\section{Design of the Experiments}

Taguchi’s L9 Orthogonal array has been adopted for designing the experiments.

1. Number of parameters $=4$

2. Number of levels for each parameter $=3$

3. Total degree of freedom (DOF) for three parameters $=4 \times(3-1)=8$

Hence, minimum number of experiments $=$ total DOF for the parameters +1

Minimum number of experiments $=8+1=9$

Table 4 shows the assignment table of L9 orthogonal array adopted in this present study.

Table 4

Assignment table of L9 Orthogonal Array for experimentation

\begin{tabular}{ccccc}
\hline & \multicolumn{3}{c}{ Columns } \\
\cline { 2 - 5 } Experiment No. & 1 & 2 & 3 & 4 \\
& $\mathrm{CS}$ & $\mathrm{FR}$ & $\mathrm{DOC}$ & $\mathrm{NR}$ \\
$\mathrm{rpm}$ & $\mathrm{mm} / \mathrm{min}$ & 0.15 & $\mathrm{~mm}$ \\
\hline 1 & 450 & 0.2 & 0.4 & 0.4 \\
\hline 3 & 450 & 0.25 & 0.6 & 0.8 \\
4 & 450 & 0.15 & 0.4 & 1.2 \\
5 & 600 & 0.2 & 0.6 & 0.4 \\
6 & 600 & 0.25 & 0.2 & 0.8 \\
7 & 600 & 0.15 & 0.6 & 0.8 \\
8 & 750 & 0.2 & 0.2 & 0.2 \\
\hline 9 & 750 & 0.25 & 0.4 & 0.4 \\
\hline
\end{tabular}




\section{Experimental procedure}

Based on above L9 array, nine experiments were conducted on Aluminum 6351-T6 Alloy, Cylindrical rod of length $100 \mathrm{~mm}$ and diameter $\mathbf{2 4} \mathrm{mm}$ on which the operation is done with selected parametric values, by using CNC turning using a carbide tool as illustrated in Fig. 1. Table 5 represents the combined measured response of $R_{a}$ and MRR after the experimentation. In this study $R_{a}$ was determined by mitutoyo surftest instrument and the Material Removal Rate (MRR) was determined by a mathematical equation, represented as:

$M R R=\pi \mathrm{x} D_{\text {avg }} \mathrm{x} f \mathrm{x} d \mathrm{x} N$

Here, $D_{\text {avg }}=\left(D_{i}-D_{f}\right) / 2, d=D O C, f=F R, N=C S$.

Table 5

Combined measured responses for $\mathrm{R}_{\mathrm{a}}$ and $\mathrm{MRR}$

\begin{tabular}{|c|c|c|c|c|c|c|c|c|}
\hline \multirow[t]{2}{*}{ Expt. No. } & \multirow{2}{*}{$\begin{array}{c}\mathrm{CS} \\
(\mathrm{rpm})\end{array}$} & \multirow{2}{*}{$\begin{array}{c}\text { FR } \\
(\mathrm{mm} / \mathrm{min})\end{array}$} & \multirow{2}{*}{$\begin{array}{l}\text { DOC } \\
(\mathrm{mm})\end{array}$} & \multirow{2}{*}{$\begin{array}{c}\mathrm{NR} \\
(\mathrm{mm})\end{array}$} & \multicolumn{4}{|c|}{ Responses } \\
\hline & & & & & $\begin{array}{c}\mathrm{R}_{\mathrm{a}} \\
(\mu \mathrm{m})\end{array}$ & $\begin{array}{c}\text { M.R.R. } \\
\left(\mathrm{mm}^{3} / \mathrm{min}\right)\end{array}$ & $\begin{array}{l}\mathrm{S} / \mathrm{N} \\
\left(\mathrm{R}_{\mathrm{a}}\right)\end{array}$ & $\begin{array}{c}\mathrm{S} / \mathrm{N} \\
(\mathrm{MRR})\end{array}$ \\
\hline 1 & 450 & 0.15 & 0.2 & 0.4 & 1.928 & 11.7855 & -5.71 & 26.198 \\
\hline 2 & 450 & 0.2 & 0.4 & 0.8 & 1.5847 & 37.638 & -4.16 & 36.2833 \\
\hline 3 & 450 & 0.25 & 0.6 & 1.2 & 1.784 & 83.463 & -3.41 & 43.201 \\
\hline 4 & 600 & 0.15 & 0.4 & 1.2 & 0.8571 & 37.278 & 1.33 & 36.2002 \\
\hline 5 & 600 & 0.2 & 0.6 & 0.4 & 4.079 & 91.296 & -10.937 & 43.980 \\
\hline 6 & 600 & 0.25 & 0.2 & 0.8 & 1.8748 & 25.83 & -5.46 & 33.0157 \\
\hline 7 & 750 & 0.15 & 0.6 & 0.8 & 1.1158 & 84.611 & -1.479 & 43.331 \\
\hline 8 & 750 & 0.2 & 0.2 & 1.2 & 1.207 & 25.11 & -1.679 & 32.708 \\
\hline 9 & 750 & 0.25 & 0.4 & 0.4 & 6.253 & 80.0625 & -15.9 & 42.83 \\
\hline
\end{tabular}

The lower the better $\mathrm{S} / \mathrm{N}$ ratio was selected for $\mathrm{R}_{\mathrm{a}}$ and was calculated using the mathematical equation,

$$
\mathrm{S} / \mathrm{N}=-10 \times \log _{10}\left[(1 / \mathrm{n}) \times \operatorname{Sum}\left(\mathrm{yi}^{2}\right)\right]
$$

Here, $\quad \mathrm{n}=$ Number of experiments

$$
\mathrm{Y}_{\mathrm{i}}=\mathrm{R}_{\mathrm{a}}
$$

The higher the better $\mathrm{S} / \mathrm{N}$ ratio was selected for MRR and was calculated using the following mathematical equation

$\mathrm{S} / \mathrm{N}=-10 \times \log _{10}\left[(1 / \mathrm{n}) \times \operatorname{Sum}\left(1 / \mathrm{y}_{\mathrm{i}}^{2}\right)\right]$

Here, $n=$ Number of experiments

$$
\mathrm{Y}_{\mathrm{i}}=\mathrm{MRR}
$$

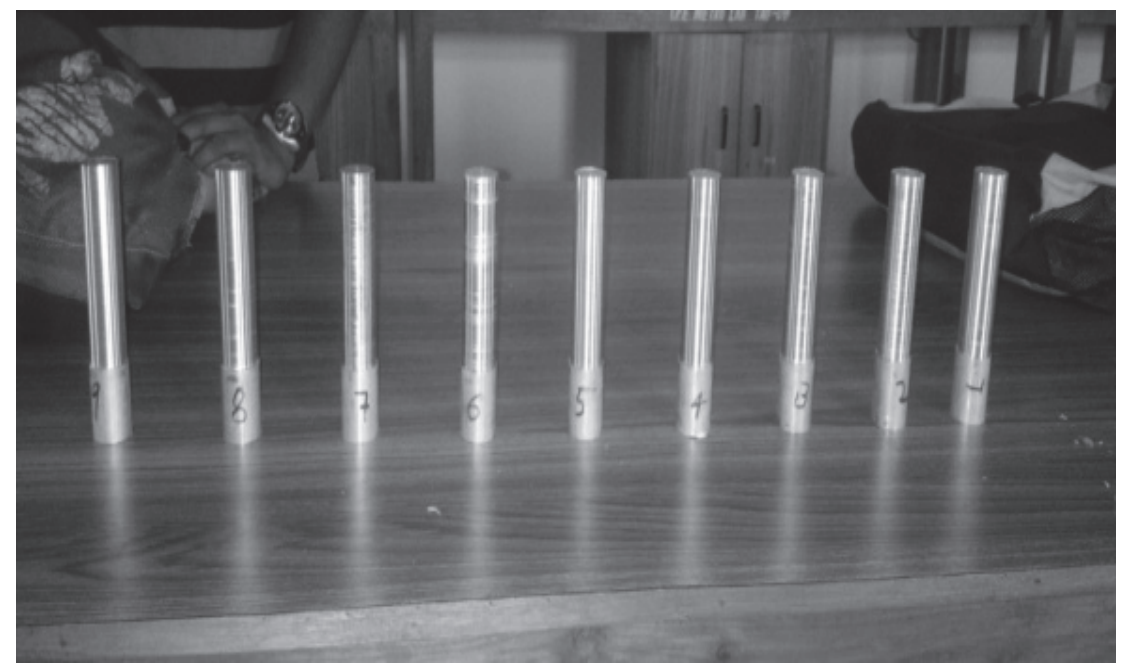

Fig. 1. Experimented Workpiece. 


\section{Result Analysis}

In this study, ANOVA is used to predict the most influencing parameter on the responses, with an optimal arrangement of levels.

\subsection{ANOVA Calculation}

Grand Total Sum (GSS) $=\sum_{i=1}^{n} Y_{i}^{2}$

with $\mathrm{n}=9$ and GSS $=72.10$.

Mean Sum of Square $(\mathrm{SSM})=\mathrm{N} \times\left(\mathrm{Y}_{\mathrm{m}}\right)^{2}=9 \times 2.298^{2}=47.53$

Total Sum of Square $(\mathrm{TSS})=\mathrm{GSS}-\mathrm{SSM}=72.10-47.53=24.57$

Sum of Square for Factor $1\left(S_{1}\right)=n \sum_{i=1}^{n}\left(Y_{1 i}-Y_{m}\right)^{2}=1.794$

Sum of Square for Factor $2\left(S_{2}\right)=n \sum_{i=1}^{n}\left(Y_{2 i}-Y_{m}\right)^{2}=6.022$

Sum of Square for Factor $3\left(S_{3}\right)=n \sum_{i=1}^{n}\left(Y_{3 i}-Y_{m}\right)^{2}=2.267$

Sum of Square for Factor $4\left(S_{4}\right)=n \sum_{i=1}^{n}\left(Y_{4 i}-Y_{m}\right)^{2}=14.47$

Sum of Square Due to All Factors $(\mathrm{SSA})=\mathrm{S}_{1}+\mathrm{S}_{2}+\mathrm{S}_{3}+\mathrm{S}_{4}=24.56$

Estimated Error (Error) $=$ TSS- SSA $=24.57-24.56=0.01$

Table 6

ANOVA Table

\begin{tabular}{|c|c|c|c|c|c|c|c|c|c|c|c|c|c|}
\hline \multirow{2}{*}{ Expt. Nos } & \multirow{2}{*}{ Response } & \multicolumn{3}{|c|}{ CS } & \multicolumn{3}{|c|}{ FR } & \multicolumn{3}{|c|}{ DOC } & \multicolumn{3}{|c|}{ NR } \\
\hline & & Level 1 & Level 2 & Level 3 & Level 1 & Level 2 & Level 3 & Level 1 & Level 2 & Level 3 & $\begin{array}{c}\text { Level } \\
1 \\
\end{array}$ & $\begin{array}{c}\text { Level } \\
2 \\
\end{array}$ & $\begin{array}{c}\text { Level } \\
3 \\
\end{array}$ \\
\hline 1 & 1.928 & 1.928 & & & 1.928 & & & 1.928 & & & 1.928 & & \\
\hline 2 & 1.585 & 1.585 & & & & 1.585 & & & 1.585 & & & 1.585 & \\
\hline 3 & 1.784 & 1.784 & & & & & 1.784 & & & 1.784 & & & 1.784 \\
\hline 4 & 0.857 & & 0.857 & & 0.857 & & & & 0.857 & & & & 0.857 \\
\hline 5 & 4.079 & & 4.079 & & & 4.079 & & & & 4.079 & 4.079 & & \\
\hline 6 & 1.875 & & 1.875 & & & & 1.875 & 1.875 & & & & 1.875 & \\
\hline 7 & 1.116 & & & 1.116 & 1.116 & & & & & 1.116 & & 1.116 & \\
\hline 8 & 1.207 & & & 1.207 & & 1.207 & & 1.207 & & & & & 1.207 \\
\hline 9 & 6.253 & & & 6.253 & & & 6.253 & & 6.253 & & 6.253 & & \\
\hline Mean & 2.298 & 1.76557 & 2.270 & 2.858 & 1.3003 & 2.290 & 3.303 & 1.669 & 2.898 & 2.326 & 4.086 & 1.525 & 1.282 \\
\hline
\end{tabular}

\subsection{For Surface Roughness $\left(R_{a}\right)$}

Table 7

ANOVA Results for $\mathrm{R}_{\mathrm{a}}$

\begin{tabular}{ccccccc}
\hline FACTOR & D.O.F & Sum Of & Mean & F calculated & F tab & P $\%$ \\
\hline CS & 2 & 2.120738874 & 1.0603694 & & & 31.59738155 \\
FR & 2 & 73.65303135 & 36.826516 & 52.09483749 & 2.866424757 \\
DOC & 2 & 6.681593922 & 3.340797 & 4.725895774 & 65.10742571 \\
NR & 2 & 151.7644511 & 75.88222555 & 107.343096 & \\
ERROR & 1 & 0 & 0 & & 0.428767984 \\
Error & 3 & 2.120738874 & 0.70691296 & & 100 \\
\hline Total & 9 & \multicolumn{7}{c}{164.8707423} & & \\
\hline
\end{tabular}

From ANOVA, nose radius is found to be the most influencing parameter on response $\mathrm{R}_{\mathrm{a}}$, which is then trailed by DOC, FR and CS and also the finest arrangement of factor, is found as follows. 
1. Speed is supposed to be kept at 750rpm i.e. at level 3.

2. Feed at $0.15 \mathrm{~mm} / \mathrm{min}$ i.e. at level 1 .

3. DOC at $0.2 \mathrm{~mm}$ i.e. at level 1 .

4. NR at $0.4 \mathrm{~mm}$ i.e. at level 1 .

From ANOVA, Depth of Cut had been found to be the most affecting variable on response MRR, trailed by FR, CS and NR and the optimum combination of factor, and is found as follows.

1. CS is supposed to be kept at 750rpm i.e. at level 3 .

2. FR at $0.25 \mathrm{~mm} / \mathrm{min}$ i.e. at level 3 .

3. DOC at $0.2 \mathrm{~mm}$ i.e. at level 1 .

4. NR at $1.2 \mathrm{~mm}$ i.e. at level 3 .

The depicted Table 7 shows ANOVA results of $\mathrm{R}_{\mathrm{a}}$ for experiment and the Fig. 2 give optimum parameter combination.
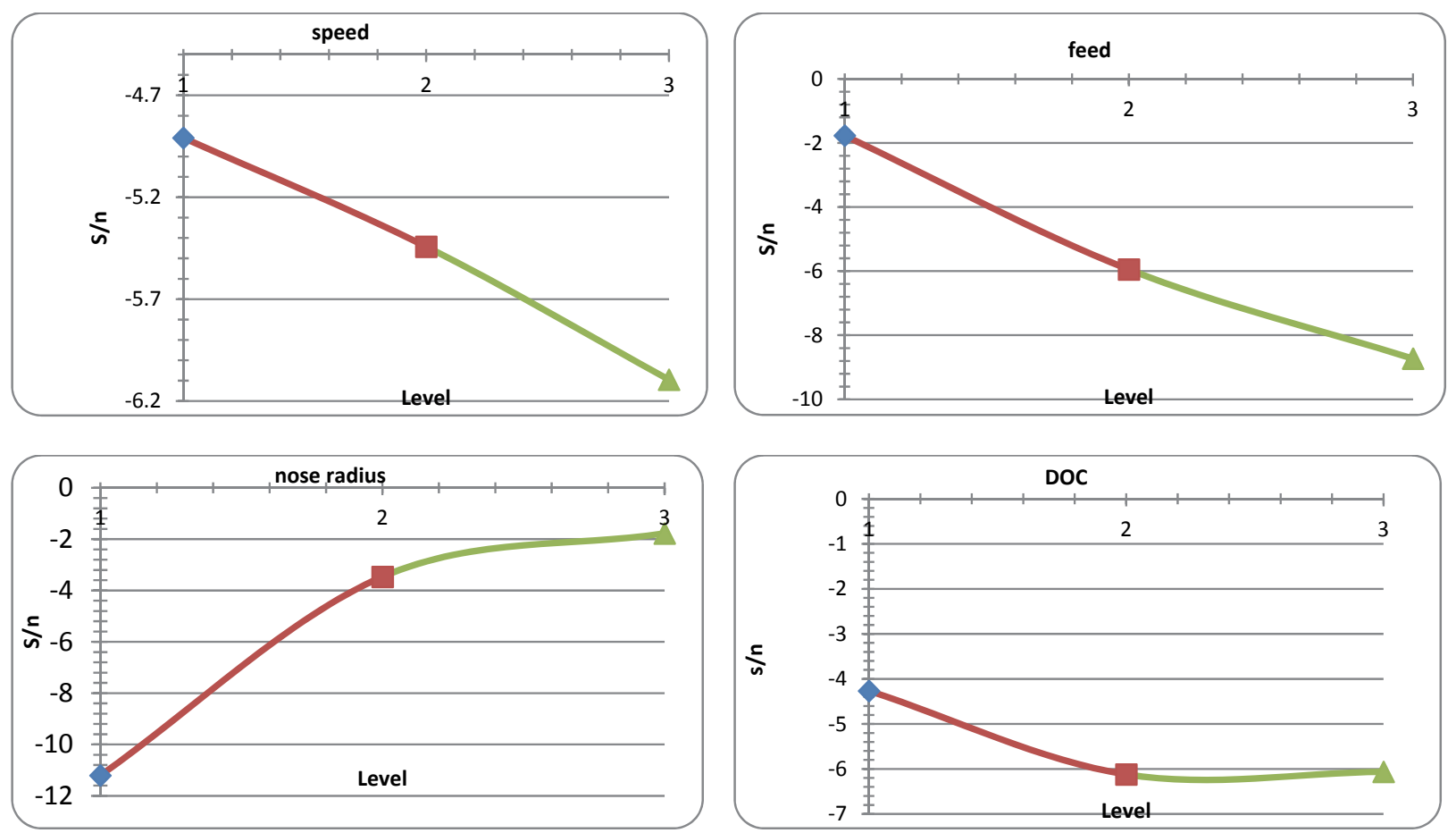

Fig. 2. $\mathrm{S} / \mathrm{N}$ vs. Parameters; showing contribution of the parameters on $\mathrm{R}_{\mathrm{a}}$

\subsection{For Material removal rate (MRR)}

Table 8

ANOVA results for MRR

\begin{tabular}{ccccccc}
\hline FACTOR & D.O.F & Sum Of Squares & Mean Square & F calculated & F tab & P\% \\
\hline CS & 2 & 29.41398136 & 14.7069907 & 367.504369 & 9.480625464 \\
FR & 2 & 29.73739262 & 14.8686963 & 371.5451362 & 9.584866405 \\
DOC & 2 & 251.0221842 & 125.511092 & 3136.323107 & 80.90871082 \\
NR & 2 & 0.12005564 & 0.06002782 & & \\
ERROR & 1 & $2.67164 \mathrm{E}-12$ & $2.6716 \mathrm{E}-12$ & & 0.025797314 \\
Error & 3 & 0.12005564 & 0.04001855 & 1 & 100 \\
\hline Total & 9 & & & 3876.372612 & \\
\hline
\end{tabular}



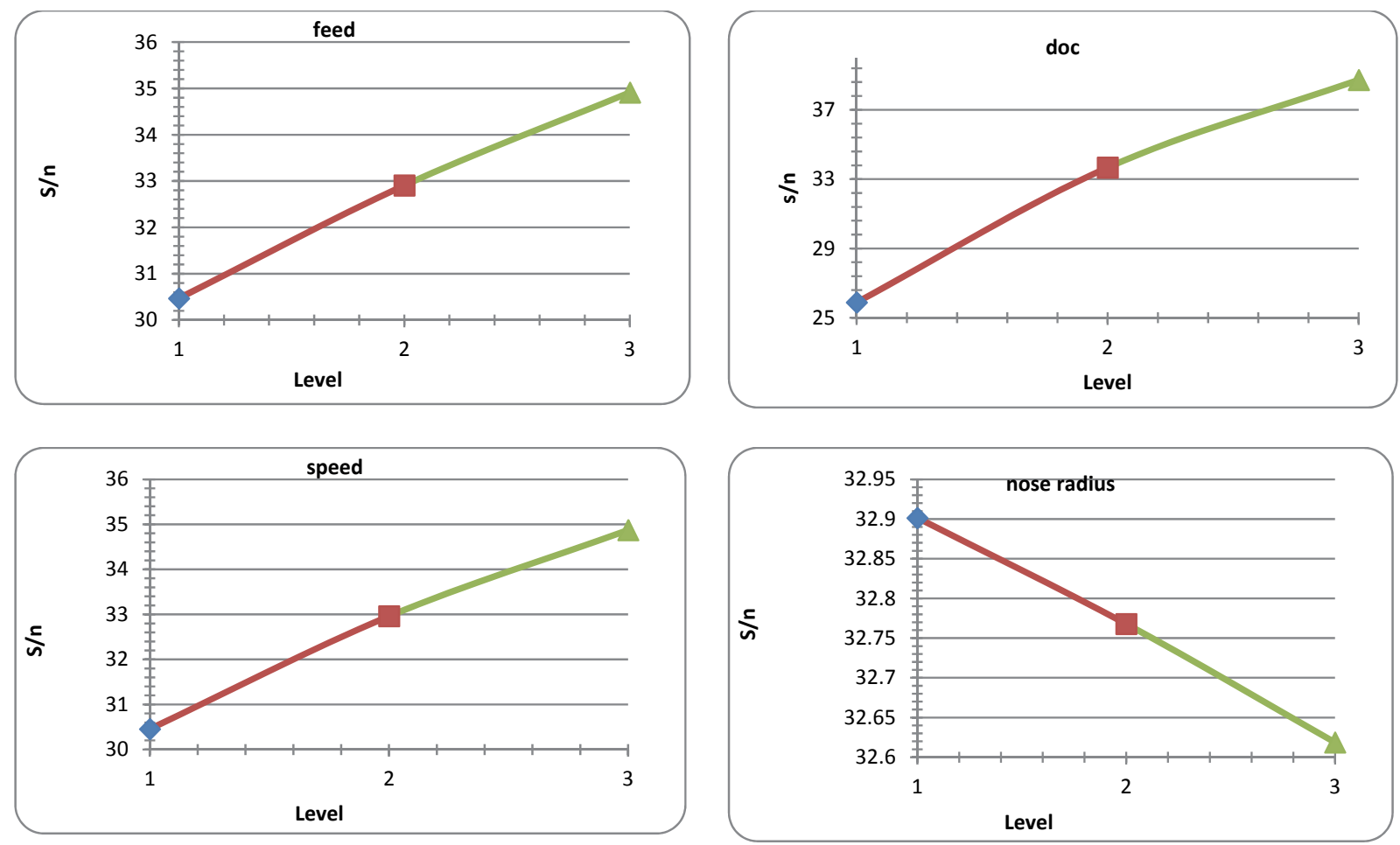

Fig. 3. S/N vs. Parameters showing contribution of the parameters on MRR

The outcome is inspected with ANOVA to recognize the significant variables, which affects MRR and $\mathrm{R}_{\mathrm{a}}$. The outcome of ANOVA is displayed in Table 7 and Table 8. The main effect of Nose Radius (the most significant parameter), depth of cut and feed rate are important for roughness of the material surface as shown in Fig. 3. DOC, FR and CS are significant parameters for MRR. The Nose Radius (65.10\%), followed by feed (31.59\%) and Depth of Cut (2.86\%) is contributing to roughness of material surface, whereas DOC (80.90\%), followed by Feed $(9.58 \%)$ and Spindle Speed $(9.48 \%)$ is contributing to Material Removal Rate. Based on ANOVA table, the optimal machining parameters for Al 6351- T6.

For surface roughness $\left(\mathrm{R}_{\mathrm{a}}\right)$ are: (based on study of graph)

a) Speed of the spindle at 750rpm (level 3)

b) Feed at $0.15 \mathrm{~mm} / \mathrm{min}($ level 1$)$

c) Depth of Cut at $0.2 \mathrm{~mm}$ (level 1)

d) Nose Radius at $0.4 \mathrm{~mm}$ (level 1)

For Material Removal Rate:

a) Speed of the spindle at $750 \mathrm{rpm}$ (level 3)

b) Feed at level $0.25 \mathrm{~mm} / \mathrm{min}$ (level 1)

c) Depth of Cut at $0.2 \mathrm{~mm}$ (level 1)

d) Nose Radius at $1.2 \mathrm{~mm}$ (level 3)

\section{Conclusions and Future Scope}

The parametric study of CNC turning process on aluminum alloy 6351-T6 using CNC turning machine was successfully undertaken. Based on initial study, L9 orthogonal array experiment plan was designed by considering NR, DOC, FR and CS as main parameters while removal rate of material and surface roughness as responses. Then based on the result of L9 orthogonal array experimentation. From the outcome obtained from the experiment, following conclusions are reached: 
1. From initial investigation for L9 array experiment, by ANOVA nose radius was found to be the most influencing parameter on roughness of the material surface and then it is trailed by feed rate and depth of cut.

2. Also, for removal rate of material; depth of cut is the most affecting parameter.

3. Finally, it is concluded that, the minimum Nose radius, feed rate and depth of cut with higher spindle speed will provide optimum surface quality and minimum depth of cut and higher speed of the spindle and feed rate leads to higher productivity.

\section{Scope for Future study}

The study is focussed on applicability of CNC turning machine to perform operation on Aluminum Alloy 6351- T6 Material, which is having various advantages and applications. The study has resulted in arriving at factor level combinations corresponding to minimum value of roughness of the surface and maximum value of material removal rate. The study may be extended as follows:

1. Further study can be made by considering more no. of parameters and responses.

2. The experiment can be conducted with higher spindle speed and different tools and work pieces.

3. A neural network can also be used for prediction.

\section{References}

Ahilan, C., Kumanan, S., \& Sivakumaran, N. (2010). Application of grey based Taguchi method in multiresponse optimization of turning process. Advances in Production Engineering \& Management, 5(3), 171-180.

Asiltürk, I., \& Neşeli, S. (2012). Multi response optimisation of CNC turning parameters via Taguchi methodbased response surface analysis. Measurement, 45(4), 785-794.

Camposeco-Negrete, C. (2013). Optimization of cutting parameters for minimizing energy consumption in turning of AISI 6061 T6 using Taguchi methodology and ANOVA. Journal of Cleaner Production, 53, 195-203.

Chandramouli, S., U. Shrinivas Balraj, and K. Eswaraiah. (2014). Optimization of electrical discharge machining process parameters using Taguchi method. International Journal of Advanced Mechanical Engineering 4.4, 425-434.

Çiçek, A., Kıvak, T., \& Ekici, E. (2015). Optimization of drilling parameters using Taguchi technique and response surface methodology (RSM) in drilling of AISI 304 steel with cryogenically treated HSS drills. Journal of Intelligent Manufacturing, 26(2), 295-305.

Elbah, M., Yallese, M. A., Aouici, H., Mabrouki, T., \& Rigal, J. F. (2013). Comparative assessment of wiper and conventional ceramic tools on surface roughness in hard turning AISI 4140 steel. Measurement, 46(9), 3041-3056.

Günay, M., \& Yücel, E. (2013). Application of Taguchi method for determining optimum surface roughness in turning of high-alloy white cast iron. Measurement, 46(2), 913-919.

Gupta, M., \& Kumar, S. (2015). Investigation of surface roughness and MRR for turning of UD-GFRP using PCA and Taguchi method. Engineering Science and Technology, an International Journal, 18(1), 70-81.

Hamdan, A., Sarhan, A. A., \& Hamdi, M. (2012). An optimization method of the machining parameters in high-speed machining of stainless steel using coated carbide tool for best surface finish. The International Journal of Advanced Manufacturing Technology, 58(1-4), 81-91.

Jayaraman, P. (2014). Multi-response optimization of machining parameters of turning AA6063 T6 aluminium alloy using grey relational analysis in Taguchi method. Procedia Engineering, 97, 197-204.

Kant, G., \& Sangwan, K. S. (2014). Prediction and optimization of machining parameters for minimizing power consumption and surface roughness in machining. Journal of Cleaner Production, 83, 151-164.

Kıvak, T. (2014). Optimization of surface roughness and flank wear using the Taguchi method in milling of Hadfield steel with PVD and CVD coated inserts. Measurement, 50, 19-28. 
Krishankant, J. T., Bector, M., \& Kumar, R. (2012). Application of Taguchi method for optimizing turning process by the effects of machining parameters. International Journal of Engineering and Advanced Technology, 2(1), 263-274.

Kuram, E., \& Ozcelik, B. (2017). Optimization of machining parameters during micro-milling of Ti6A14V titanium alloy and Inconel 718 materials using Taguchi method. Proceedings of the Institution of Mechanical Engineers, Part B: Journal of Engineering Manufacture, 231(2), $\quad$ 228-242.

Lin, M. Y., Tsao, C. C., Huang, H. H., Wu, C. Y., \& Hsu, C. Y. (2015). Use of the grey-Taguchi method to optimise the micro-electrical discharge machining (micro-EDM) of Ti-6Al-4V alloy. International Journal of Computer Integrated Manufacturing, 28(6), 569-576.

Lodhi, B. K., \& Agarwal, S. (2014). Optimization of machining parameters in WEDM of AISI D3 steel using Taguchi technique. Procedia CIRP, 14, 194-199.

Mia, M., \& Dhar, N. R. (2017). Optimization of surface roughness and cutting temperature in high-pressure coolant-assisted hard turning using Taguchi method. The International Journal of Advanced Manufacturing Technology, 88(1-4), 739-753.

Roy, S., Davim, J. P., \& Kumar, K. (2017). Optimization of process parameters using Taguchi coupled genetic algorithm: machining in CNC lathe. In Mathematical Concepts and Applications in Mechanical Engineering and Mechatronics (pp. 67-93). IGI Global.

Sahoo, P., Pratap, A., \& Bandyopadhyay, A. (2017). Modeling and optimization of surface roughness and tool vibration in CNC turning of Aluminum alloy using hybrid RSM-WPCA methodology. International Journal of Industrial Engineering Computations, 8(3), 385-398.

Said, M. S., Ghani, J. A., Selamat, M. A., Wan, N. N. I., \& Che, H. C. (2016). Optimisation of end milling machining parameters using the Taguchi method and ANOVA of AlSi/AlN metal matrix composite material. In Key Engineering Materials(Vol. 701, pp. 200-204). Trans Tech Publications.Rao, C. J., Rao, D. N., \& Srihari, P. (2013). Influence of cutting parameters on cutting force and surface finish in turning operation. Procedia Engineering, 64, 1405-1415.

Selvaraj, D. P., Chandramohan, P., \& Mohanraj, M. (2014). Optimization of surface roughness, cutting force and tool wear of nitrogen alloyed duplex stainless steel in a dry turning process using Taguchi method. Measurement, 49, 205-215.

Sreenivasulu, R. (2013). Optimization of surface roughness and delamination damage of GFRP composite material in end milling using Taguchi design method and artificial neural network. Procedia Engineering, 64, 785-794.

Verma, J., Agrawal, P., \& Bajpai, L. (2012). Turning parameter optimization for surface roughness of ASTM A242 Type-1 alloys steel by Taguchi method. International Journal of Advances in Engineering \& Technology, 3(1), 255-261.

Zerti, O., Yallese, M. A., Khettabi, R., Chaoui, K., \& Mabrouki, T. (2017). Design optimization for minimum technological parameters when dry turning of AISI D3 steel using Taguchi method. The International Journal of Advanced Manufacturing Technology, 89(5-8), 1915-1934.

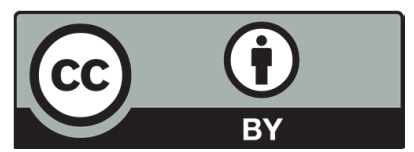

(C) 2017 by the authors; licensee Growing Science, Canada. This is an open access article distributed under the terms and conditions of the Creative Commons Attribution (CCBY) license (http://creativecommons.org/licenses/by/4.0/). 